FGDP(UK) \& CGDent

\section{launch UK guidelines for safe return to practice}

The FGDP(UK) and newly formed College of General Dentistry have launched guidelines for a safe return to general dental practice.

Implications of COVID-19 for the safe management of general dental practice - a practical guide is in line with other FGDP(UK) guidance and standards publications and adopts the ABC (Aspirational, Basic, Conditional) approach to measures with 'basic' measures being a minimum standard

The guidance is divided into five sections - four of which reflect the patient journey and the fifth concerns general management of the practice. These sections are assigned a risk status and $\mathrm{ABC}$ based risk mitigation measures to ensure safe practice and include:

I. Pre-appointment - including the important role of digital communication to minimise contact time

II. Patient attendance (pre-treatment) - including the communication of new infection control and prevention procedures to patients along with changes to waiting areas

III. During treatment - including recommendations for approaches to aerosol generated exposures (AGEs), developed using a model based on risk continuum and recommendations for appropriate levels of PPE

IV. After treatment - including procedures to protect patients and staff and the use of an appropriate fallow period following high risk AGEs

V. Management/governance tasks including risk assessments for all staff members and awareness of the need to encourage staff to monitor and support if they feel unwell.

For further information and to access a full copy of the guidance visit www. fgdp.org.uk/implications-covid-19-safemanagement-general-dental-practicepractical-guide

\title{
Denplan makes significant investment in PPE
}

Denplan, part of Simplyhealth, has announced that it is investing $£ 2$ million to provide essential, fully-certified personal protective equipment (PPE) to help its Denplan member dentists get safely back to work and protect and care for their patients.

As the UK's leading dental payment plan specialist, Denplan has over 2 million customers with around 6,700 member dentists, as well as serving over 2,700 companies with Denplan employee benefit schemes.

With a return to work date of Monday 8 June set by the Chief Dental Officer for England, Denplan has made the decision to invest in PPE as part of a number of support measures put in place since lockdown began to help their member dental practices survive, make sure they can reopen safely, and also to ensure that their patients are confident to start attending appointments again.

Romana Abdin, Chief Executive at Simplyhealth, said: 'Coronavirus has affected all of us deeply, both at work and in our personal lives. As a company, we are incredibly passionate about our Purpose which is to provide access to affordable healthcare for the many which we have been delivering for 148 years. This investment, alongside the range of support measures we have provided since lockdown, demonstrates our Purpose in action, our continued support for our Denplan members, our commitment to the longterm success of the dental industry, and the provision of essential dental healthcare to our members' patients.'

Qualifying Denplan member practices will be allocated a fund, based on their Denplan patient numbers, which they can use to order vital PPE equipment directly from the chosen supplier. This fund will allow Denplan practices to select from a range of PPE items to help ensure the safety of their patients and of Denplan dental teams.

Catherine Rutland, Clinical Director at Denplan, said: 'This has been such a difficult time for the whole dental profession. Our aim is to support our members in returning to practice by providing the standard of guidance that they expect from us, to provide safe practice and the PPE to enact that. We have also been working closely with our members to provide clinical and business guidance to help them return to work once all official government guidelines can be adhered to safely. We have always strived to create a partnership with our members' and have worked hard to ensure that we provide added value services from our clinical team and our dedicated business consultants to contribute to a successful dental practice for the long term.'

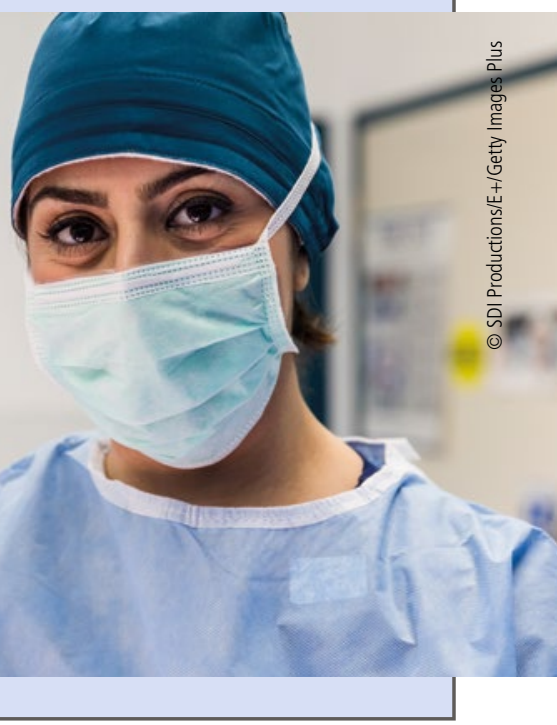

\section{Date for the diary}

Align Technology has announced its Growth Summit will be moving to a virtual platform.

The Summit, originally scheduled for Dubrovnik, will be a full two-day symposium broadcast on 19 and 20 June 2020.

For more on the Summit, to view the speakers and details on how to sign up visit http://aligngrowthsummit.com/ 